\title{
¿Preparados para la autonomía curricular en educación básica?
}

\author{
Are we ready for the curricular autonomy \\ in basic education?
}

En el Modelo educativo 2017 hay un elemento que, en nuestro país, es bastante novedoso: la "autonomía curricular", que corresponde a uno de los tres componentes que articulan los nuevos planes y programas de estudio para lograr el desarrollo de los aprendizajes clave propuestos para la educación básica. Los otros dos componentes curriculares son los Campos de formación académica y las Áreas de desarrollo personal y social.

En el documento emitido por la SEP (2017a), se dice que, en congruencia con los principios de equidad e inclusión educativas, la autonomía curricular busca atender las necesidades e intereses educativos específicos de cada educando. De esta suerte, cada escuela determinará la oferta de contenidos que requiere para sus estudiantes, tomando en consideración tanto las horas lectivas que tenga disponibles, como los principios establecidos en el Plan de estudios y los lineamientos que expedirá la SEP en 2018.

El Modelo educativo 2017 sostiene que la autonomía curricular se traducirá en beneficios para alumnado, cuerpo docente y escuelas. En cuanto al primero, porque tendrán oportunidad de aprender temas de su interés, desarrollar nuevas habilidades, superar dificultades, fortalecer sus conocimientos, su identidad y sentido de pertenencia. El cuerpo docente se beneficiará porque habrá espacios para experimentar con nuevas metodologías que les permitan renovar su práctica, tales como el Aprendizaje basado en problemas, el Trabajo por proyectos y el Estudio de casos", entre otras. Para las escuelas, la autonomía curricular aspira a sentar las 
bases para que en cada una sea posible, con la ayuda del Consejo Técnico Escolar, renovar y replantear estrategias y compromisos para fomentar el trabajo colaborativo y colegiado (SEP, 2017b).

Todo lo anterior se concretará mediante propuestas curriculares definidas por las escuelas con base en los intereses de sus estudiantes y de las propias fortalezas, capacidades y recursos institucionales. Habrán de responder a los cinco ámbitos que, por lo pronto, organizan 108 posibilidades que la SEP pondrá a disposición de los centros escolares, a saber:

- Profundización en la formación académica; donde hay 23 opciones, entre ellas: talleres de escritura creativa, inglés, debates, matemáticas lúdicas, tecnología, huerto escolar, computación.

- Potenciar el desarrollo personal y social, con 33, dentro las cuales están: nutrición; futbol, béisbol, basquetbol; orquestas escolares; talleres de teatro, danza, pintura; convivencia escolar; habilidades sociales, liderazgo.

- Nuevos contenidos relevantes, también con 23 alternativas: uso inteligente de redes sociales; reciclaje, educación financiera; programación; cultura de la legalidad, equidad de género.

- Contenidos regionales y locales, con 18 posibilidades, algunas son: microhistoria. talleres de tecnologías, artesanías locales, cultivo de hortalizas y plantas medicinales; educación ambiental contextualizada.

- Impulso a proyectos de impacto social, con 11 opciones, entre ellas: limpieza de basura en la comunidad, potabilización del agua escolar y comunitaria, democracia escolar, eliminación de barreras de aprendizaje.

Aunque no hay datos públicos sobre la distribución de la oferta de opciones para atender la autonomía curricular, es razonable advertir que esta tenderá a concentrarse en las ciudades más grandes del país, donde se encuentra la mayor parte de las escuelas privadas que, en principio, no tendrán dificultades para contar con los recursos financieros necesarios para adquirir los bienes y servicios asociados. A la par, ha de considerarse que para las empresas y organizaciones ofertantes no resulta rentable llevar sus servicios a poblaciones medianas y pequeńas. En congruencia con 
el principio de inclusión y equidad del Modelo Educativo 2017, parece necesario asegurar estrategias que permitan compensar la posible desventaja que representa ubicarse en comunidades de menor tamańo. No se sabe si la SEP ha tenido en cuenta estas diferencias en las estimaciones financieras ni cuál será el criterio que utilizará para asignar los recursos a las escuelas.

La innovación demanda muchos cuidados, por ejemplo, el tema de los recursos requeridos por cada tipo de servicio y la formación al cuerpo directivo y docente para atenderla. Las escuelas financiarán sus decisiones con los dineros que la SEP envíe para tal efecto; por el momento, está previsto que las escuelas de tiempo completo (24507) que reciben recursos directos y cuya jornada diaria es más larga que la de las escuelas regulares, los utilicen para el buen funcionamiento de la autonomía curricular. Obviamente, la cantidad de horas semanales que pueden destinarse a la autonomía curricular es mayor en las escuelas de tiempo completo que en las que no pertenecen a este programa. En educación preescolar, una escuela de jornada regular puede dedicar 2 horas semanales, pero una de tiempo completo hasta 27 ; en educación primaria, tales cifras son, respectivamente, 2.5 y 20 , mientras que en secundaria son 4 y 14 . ¿Cómo asegurar que estas diferencias no se traduzcan en desigualdad de oportunidades de aprendizaje para las instituciones?

En la Ruta de implementación que ha definido la SEP para operar los distintos programas y acciones que dan concreción al Modelo educativo está previsto realizar un piloto para el componente de autonomía curricular en 1162 escuelas públicas de educación básica, durante el ciclo escolar 2017-2018. Se sabe que la Secretaría permitió a los estados elegir las escuelas participantes, cuidando las proporciones que se establecen en la Ruta mencionada para cada nivel y tipo de escuela en todo el país (SEP, 2017b: 18). No obstante, es deseable saber cómo está conformado ese conjunto de escuelas, de manera que sea factible estimar si en algún sentido representan al muy diverso universo de planteles. De igual forma, es deseable tener información acerca los aspectos cuyo estudio o comprensión se va a priorizar en el piloto, y qué le interesa a la SEP saber sobre el funcionamiento de este componente curricular.

Según los documentos oficiales, se espera que a través del Servicio de Asistencia Técnica a la Escuela (SATE), y con el apoyo 
de supervisores, asesores técnico-pedagógicos y directivos destacados, las escuelas cuenten con asesoría y acompañamiento para aprender a gestionar su autonomía curricular. Pero lo cierto es que el SATE aún no funciona y que los lineamientos expedidos recientemente (SEP, 2017d) no hacen mención de este componente curricular. Sin una vinculación normativa explícita, ¿cómo harán las escuelas para solicitar apoyo y ejercer esta nueva atribución?

Como se ha dicho ya, otro aspecto ideado en la política es que las escuelas elijan propuestas curriculares que respondan a intereses, necesidades y contextos específicos de sus estudiantes, tras el debido análisis y discusión en grupos colegiados (CTE) y con participación de ellos y sus familias. Lo anterior implica claridades que aún no están expresadas, como por ejemplo, ¿cuáles son los criterios que utilizarán las escuelas para definir dichas necesidades e intereses? ¿Qué evidencia se considerará válida para la elección de ámbitos y propuestas? ¿Qué tanto pesarán las opiniones de estudiantes?

Nos parece interesante que se abra este espacio de innovación a las escuelas y esperamos que los resultados del piloto sirvan de base para informar sobre los ajustes que se requieren, atendiendo a la diversidad de condiciones de implementación y gestión. La aplicación de la autonomía curricular merece la pena, pero hay que evitar la tentación de generalizarla antes de entender mejor las exigencias de su adecuado funcionamiento.

\section{REFERENCIAS BIBLIOGRÁFICAS}

SEP. Modelo Educativo para la Educación Obligatoria, México, SEP, 2017a.

SEP. Ámbitos de la Autonomía Curricular, México, SEP, 2017b. Disponible en http://www.aprendizajesclave.sep.gob.mx/ descargables/AMBITOS_AUTONOMIA_CURRICULAR.pdf

SEP. Ruta para la implementación del Modelo Educativo, México, SEP, 2017c.

SEP/CNSPD. Lineamientos generales para la prestación del Servicio de Asistencia Técnica a la Escuela en la Educación Básica, México, SEP, 2017d. Disponible en https://www.gob. $\mathrm{mx} / \mathrm{cms} /$ uploads/attachment/file/225920/LINEAMIENTOS_ SAT_may25_2017.pdf 